\title{
PAPER
}

\section{New steroids and new salicylates in inflammatory bowel disease: a critical appraisal}

\section{Campieri}

Gut 2002;50(Suppl III):iii43-iii46

\begin{abstract}
Although new salicylates are now available for the treatment of ulcerative colitis, sulphasazaline still has an important therapeutic role. The role of salicylates in Crohn's disease is limited to the mild activity phase; further data are required to clarify its role in maintenance on remission. New steroids are a real alternative to traditional steroids in active ulcerative colitis and Crohn's disease.
\end{abstract}

1 n the 1930s, a Swedish doctor, Svartz, ${ }^{1}$ in the effort to obtain a new drug for rheumatoid arthritis, combined a salicylate (5aminosalicylic acid, 5-ASA) with a sulphonamide (sulphapiridine, SP) in a molecule named salicylazosulphapiridine (sulphasazaline, SSP). The first results in rheumatoid arthritis were not impressive, but when she used this molecule in patients with arthritis and ulcerative colitis (UC), she had encouraging results. The introduction of SSP in the treatment of UC opened two new therapeutic options in this disease: a valid alternative to glucocorticosteroid (GCS) treatment in active disease; and the concept of maintenance treatment. In order to identify the active therapeutic moiety of SSP, Azad Khan ${ }^{2}$ compared enemas of SSP, SP, or 5-ASA in the treatment of patients with active UC. It was found that pronounced histological improvement occurred equally frequently with SSP and 5-ASA, whereas SP had virtually no effect. These results suggested that SSP has the capacity to reach the colon intact and then to liberate 5-ASA, which is the active agent. The SP appeared to act simply as a carrier which permits this to happen.

Despite the proven efficacy of this drug, the high incidence of dose related and non-dose related side effects, occurring in up to $45 \%$ of patients, limit its usefulness. The recognition that most of the side effects were related to the SP component and that 5-ASA was the active moiety, led pharmaceutical companies to prepare a wide range of 5-ASA preparations able to reach the lower part of the gastrointestinal tract. In the past two decades, the major efforts were employed to find alternative 5-ASA delivery systems. This aim was achieved in two ways: by a coating that dissolves at alkaline $\mathrm{pH}$ (Eudragit $\mathrm{S}, \mathrm{pH}>7$; Eudragit $\mathrm{L}, \mathrm{pH}>6$; microsphere formulation enveloped with ethylcellulose), which is the $\mathrm{pH}$ present in the terminal ileum; or by substitution of SP with another carrier that allows it to reach the colon and to deliver the active moiety, following splitting of the diazo bond by bacteria.

\section{EFFICACY AND TOLERANCE OF THE NEW PREPARATIONS}

Oral aminosalicylate therapy is, today, the "first line" therapy in patients with mild to moderate extensive UC; in several countries, these have completely replaced SSP. Up to $80 \%$ of treated patients show a clinical response with $2-4.8 \mathrm{~g} /$ day mesalamine. However, these products are more expensive and have been shown to cause adverse effects in some patients. A meta-analysis ${ }^{3}$ of prospective, randomised, double blind, placebo or SSP controlled trials showed that 5-ASA was more effective than placebo in the treatment of active disease and in maintenance of remission. A trend in favour of a slight benefit for the newer 5-ASA preparations over SSP in active disease was observed. There is only a modest difference in maintenance of remission between the two treatments.

The response rate of SSP in clinical trials was dose related. The new 5-ASA preparations required approximately $40 \%$ of the dose compared with the parent compound; a corresponding dose of 5-ASA up to $10 \mathrm{~g}$ of SSP was commonly prescribed. An additional advantage of mesalazine compared to SSP was the absence of dose related intolerance or toxicity, which limited the clinical utility of SSP at the highest doses. With rare exceptions, most patients intolerant to SSP will tolerate an oral or rectal form of aminosalicylates. The overall incidence of adverse events and withdrawals in the trials was significantly more frequent with SSP than with 5-ASA. This difference was not found in maintenance of remission, suggesting that these patients tolerate SSP better at these low doses than do patients with active disease.

These observations suggest that SSP is an effective and cheaper therapy that could be used in a subgroup of tolerant patients.

There have been too few clinical trials to distinguish between mesalazine formulations. Recently, however, balsalazide, a prodrug in which 5-ASA is linked with a diazo bond to an inert and biologically inactive carrier molecule, was compared with mesalazine in patients with active UC. ${ }^{4}$ After 8 and 12 weeks of treatment, 54\% and $62 \%$ of patients in the balsalazide group were in remission, compared to $22 \%$ and $37 \%$ in the mesalazine group, respectively. Moreover, balsalazide was more tolerable than mesalazine,

Abbreviations: 5-ASA, 5-aminosalicylic acid; $\mathrm{BDP}$, beclomethasone diproprionate; $\mathrm{CD}, \mathrm{Crohn}$ 's disease; CIR, controlled ileal release; GCS, glucocorticosteroid; IBD, inflammatory bowel disease; SP, sulphapyridine; SSP, sulphasalazine; UC, ulcerative colitis 
causing fewer side effects. Similar results were obtained in another study that compared balsalazine to mesalazine in the maintenance of remission in UC patients. ${ }^{5}$ There were no differences in tolerance and incidence of side effects between the two groups.

The good tolerance of 5-ASA formulations contributed to inclusion of the maintenance treatment in practical guidelines. This chronic treatment changed the natural history of the disease; there was the lowest incidence of severe relapse in the past decade.

The major innovation in the treatment of UC was the introduction of topical formulations. Rectally administered preparations of 5-ASA should be the preferred treatment for mild to moderate left sided or distal UC. These preparations include suppositories, foams, and liquid enemas, which differ in their physicochemical properties and potential for proximal spread. Administering 5-ASA rectally offers the advantage of delivering the treatment directly to the site of maximum inflammation, while potentially minimising the frequency of systemic side effects.

Dose-response effects of topical therapy have been studied in several controlled trials which confirm the absence of an initial dose-response between 1 and $4 \mathrm{~g} /$ day $^{6}{ }^{6}$

Marshall and Irvine, ${ }^{7}$ in a meta-analysis, showed that rectal 5-ASA was superior to placebo and rectal GCS in the treatment of active left sided UC. Several studies showed that topical 5-ASA (suppositories or enemas) was superior to oral mesalazine in the treatment of this disease, with good tolerance and patient compliance. Combination treatment with oral and rectal mesalazine is more effective than a single agent and is useful in patients with refractory disease. ${ }^{8-17}$

Topical 5-ASA also has an important role in maintenance of remission. While dose ranging trials for topical therapy have not been performed, dose interval trials have shown a dose interval benefit between alternate night dosing or every third night dosing.

\section{THE ROLE OF SALICYLATES IN CD}

The role of 5-ASA in active CD was established by a large placebo controlled American trial to show the efficacy of mesalazine at $4 \mathrm{~g} /$ day; this led to the clinical use of mesalamine for mild to moderate CD. Because of their low toxicity and good tolerability, aminosalicylates were a promising choice in maintenance of medical and surgical induced remission in CD.

The results of studies in maintenance treatment are conflicting; in a meta-analysis, Cammà and colleagues found that mesalazine only reduces the risk of symptomatic relapse in patients with surgically induced remission, ileitis, and prolonged disease duration. ${ }^{18}$ This conclusion, however, was recently challenged.

The role of mesalazine in the prevention of post-surgical relapse, seems to be well established. Caprilli and colleagues, ${ }^{19}$ in 110 postoperative patients, found that Asacol (5-aminosalicylic acid) $2.4 \mathrm{~g} /$ day reduced the clinical (from $41 \%$ to $18 \%$ ) and endoscopic (from $85 \%$ to $52 \%$ ) recurrence rates at 24 months. This was not, however, a double blind study (the control group did not receive placebo); furthermore, the clinical recurrence rates in the control group were rather low.

McLeod and colleagues ${ }^{20}$ treated 163 patients who had undergone surgical resection with mesalazine $3 \mathrm{~g} /$ day. After three years follow up, $31 \%$ of patients in the mesalazine group had a clinical recurrence compared with $41 \%$ in the control group $(\mathrm{p}=0.031)$.

Gendre and colleagues ${ }^{21}$ reported a muticentre French study of 161 patients given $2 \mathrm{~g}$ /day Pentasa (mesalamine) or placebo. They stratified patients into groups of presumed high risk for early relapse or lower risk. Pentasa reduced relapse rate in the high risk group compared with placebo ( $29 \%$ versus $45 \%$ ). A Canadian study ${ }^{22}$ of 293 patients did not confirm these conclusions, but did find that Pentasa $3 \mathrm{~g}$ /day reduced clinical relapse rates overall compared with placebo (25\% versus $36 \%$, a result that did not quite reach statistical significance) and somewhat prolonged the asymptomatic interval.

Brignola and colleagues ${ }^{23}$ treated 87 patients with either 3 $\mathrm{g} /$ day Pentasa or placebo for one year; the frequency of severe endoscopic recurrence was $24 \%$ in the mesalazine group and $56 \%$ in the placebo group, but the rate of clinical symptomatic recurrence was similar.

Because of the mixed results and trends towards improvement of mesalazine reported by some studies, meta-analysis has been used to try to clarify the issue. Several different drug regimens were compared and the patient populations were not homogeneous. Cammà et al found an overall decrease in relapse rate of $13.1 \%$ with mesalazine, especially after surgical resection, for ileal disease and in those with prolonged disease. ${ }^{18}$

Recently, Lochs and colleagues ${ }^{24}$ published a randomised, double blind, placebo controlled study on mesalazine $4 \mathrm{~g}$ /day in the prevention of clinical recurrence. A total of 318 patients were studied; mesalazine failed to improve remission rate after 18 months of treatment. Statistical significance was reached only in the subgroup with isolated ileal disease.

Cammà et al revised their meta-analysis to include this study, and determined that the risk reduction was $10 \%$ with mesalazine, corresponding to a number needed to treat of 10 .

Sutherland excluded the Caprilli et al study (which reported the greatest benefit for 5-ASA, but was not blinded and therefore may have been subject to bias) from the above meta-analysis, and found an overall risk difference of $8 \%$; the NNT (number of patients needed to treat) to prevent one relapse was $12 . .^{25} 26$

It is therefore difficult to recommend mesalazine in the postoperative setting: the improvement in recurrence rate is small and, even though it is a safe agent, the cost ot its routine use would be considerable.

\section{GLUCOCORTICOSTEROIDS IN IBD}

Several uncontrolled trials between 1950 and 1970 showed that GCS and ACTH are helpful in the treatment of Crohn's disease (CD). In 1979 the National Cooperative Crohn's Disease Study ${ }^{27}$ showed in a randomised, prospective, double blind, placebo controlled trial that prednisone 0.25-0.75 $\mathrm{mg} / \mathrm{kg} /$ day (according to the Crohn's Disease Activity Index) led to an improvement in $60 \%$ of treated patients compared to $30 \%$ in the placebo group. Moreover, treatment with prednisone was superior to sulphasalazine (SSP) and azathioprine (AZA). Subsequently, the European Crohn's Disease Study ${ }^{28}$ published the results obtained with 6-methylprednisolone 48 $\mathrm{mg} /$ day (fixed dose for all patients) for seven days and weekly tapering to $8 \mathrm{mg} /$ day. Eighty three per cent of the patients treated with 6-methylprednisolone were in remission before week 18 compared with 50\% in the SSP group and 38\% in the placebo group. Even better results were obtained in GETAID's studies, where prednisone $1 \mathrm{mg} / \mathrm{kg} /$ day was administered for 3-7 weeks and then tapered in steps of 5-10 mg per 10 days to complete discontinuation. ${ }^{29}$ This schedule is able to induce clinical remission in more than $90 \%$ of patients. The length of GCS treatment, moreover, does not seem to influence the remission rate after cessation of treatment ( $85 \%$ after 7 weeks versus $87 \%$ after 15 weeks). ${ }^{30}$ Two open questions on GCS treatment concern steroid dependence $(36 \%$ after the first steroid course in Copenhagen county) $)^{31}$ and steroid related side effects (table 1 ).

\section{THE NEW STEROIDS}

Non-systemic GCS have been used for several years for the inhalation treatment of asthma and very few steroid related side effects have been found. Budesonide and beclomethasone 
Table 1 Steroid toxicity

Adrenal suppression (varies with dose and duration)

Osteoporosis (bone density 2SD below controls, 33\%)

Psychiatric effects (1.3-18.4\%)

Infectious complications (relative risk 1.6\%)

Glucose intolerance (4 times greater than controls)

Cutaneous effect s $(50-54 \%)$

Cushingoid (4 times greater than controls)

Hypertension (4-5 times greater than controls)

Posterior subcapsular cataracts $(9 \%)$

Osteonecrosis (1-2\%)

dipropionate, and to a lesser extent, fluticasone propionate, tixocortol pivalate, and prednisolone metasulphobenzoate have been tested in patients with IBD.

\section{Budesonide controlled ileal release (CIR)}

Budesonide is a non-halogenated GCS, structurally related to $16 \alpha$-hydroxyprednisolone. The drug is a 1:1 mixture of two epimers, $22 \mathrm{R}$ and $22 \mathrm{~S}$. Its chemical name is $16 \alpha$-butylidenedioxypregna-1,4-diene-11 $\beta, 21$-diol-3,20-dione. Budesonide CIR capsules consist of hard gelatine filled with enteric coated spherical granules containing budesonide. In addition to being practically insoluble in gastric juice, the granules have extended release properties adjusted to release budesonide during passage through the small bowel. The pharmacokinetic profile of budesonide favours a high topical efficacy, because of rapid uptake by mucosal tissue, and high GCS affinity, while minimising the risk of systemic effects as a result of efficient hepatic inactivation. These features help to ensure that treatment with budesonide is well tolerated and that patient compliance is maintained. Oral administration of budesonide results in rapid and complete absorption. However, because of the extensive first pass hepatic biotransformation, systemic bioavailability following an oral dose of plain budesonde is low, approximately $10 \%$. Furthermore, the principal metabolites of budesonide are of low potency, displayng less than $1 \%$ of the GCS receptor affinity of their parent compound. The metabolites are removed by urinary excretion. ${ }^{32} 33$ Rectal preparations have similar characteristics to those of oral preparations

\section{Beclomethasone dipropionate (BDP)}

The chemical name of BDP is $9 \alpha$-cloro-1 $1 \beta, 17 \alpha, 21$-trihydroxy16 $\beta$-methylpregna-1,4-diene-3,2-dione-17,21-dipropionate. The pharmacokinetic profile of BDP favours a high topical efficacy, as a result of rapid uptake by mucosal tissue, and high GCS affinity, while minimising the risk of systemic effects as a result of efficient hepatic inactivation. The metabolite is removed by urinary and biliary excretion.

\section{Results in controlled studies}

In UC, new steroids have mainly been tested as rectal preparations in patients with left sided or distal colitis. All trials showed that efficacy of budesonide and beclomethasone is comparable to or superior to that of prednisone and comparable to or slightly inferior to that of 5-ASA. Combination treatment with 5-ASA and beclomethasone is superior to either drug alone.

Budesonide CIR has been used in patients with active CD with good clinical results. ${ }^{34}{ }^{35}$ Greenberg and colleagues, ${ }^{35}$ in a randomised, placebo controlled, dose finding study, tested three different doses of budesonide (3, 9, and $15 \mathrm{mg} /$ day) in patients with active CD. After eight weeks of treatment, remission occurred in $51 \%$ of patients in the group receiving $9 \mathrm{mg}, 43 \%$ in patients receiving $15 \mathrm{mg}$, and 33\% in patients receiving $3 \mathrm{mg}$, compared with $20 \%$ of those receiving placebo.

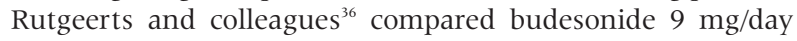

with prednisolone $40 \mathrm{mg} /$ day in the treatment of patients with mild to moderate active CD. At 10 weeks, $53 \%$ of patients treated with budesonide were in remission compared with $66 \%$ of those treated with prednisolone $(\mathrm{p}=0.12)$. These data were confirmed by Campieri and colleagues, ${ }^{37}$ who tested budesonide $9 \mathrm{mg}$ once daily with budesonide $4.5 \mathrm{mg}$ twice daily or prednisolone $40 \mathrm{mg} /$ day in the treatment of patients with mild to moderate active CD. After eight weeks of treatment, remission occurred in $60 \%$ of patients treated with budesonide $9 \mathrm{mg}$ once daily or prednisolone and in $42 \%$ of those treated with budesonide twice daily $(\mathrm{p}=0.062)$. Budesonide CIR $9 \mathrm{mg}$ /day was compared with mesalazine $4 \mathrm{~g} /$ day in mild to moderate active CD by Thomsen et al. After 16 weeks, $62 \%$ of patients treated with budesonide were in remission compared to $36 \%$ of those treated with mesalazine $(\mathrm{p}<0.001){ }^{38}$

In maintenance therapy, budesonide $6 \mathrm{mg} /$ day has been shown to be significantly more efficacious than placebo in prolonging time to relapse in CD. Löfberg and colleagues, ${ }^{39}$ in a placebo controlled one year study, compared the efficacy of budesonide 3 and $6 \mathrm{mg} /$ day and placebo for maintenance of remission in patients with ileal and ileocaecal CD. The median time to relapse was 258 days in the $6 \mathrm{mg}$ group, 139 days in the $3 \mathrm{mg}$ group, and 92 days in the placebo group $(\mathrm{p}=0.021)$. In a similar study, Greenberg and colleagues ${ }^{40}$ obtained a median time to relapse of 178 days in the $6 \mathrm{mg}$ group, 124 days in the $3 \mathrm{mg}$ group, and 39 days in the placebo group $(\mathrm{p}=0.027)$. Oral budesonide $6 \mathrm{mg} /$ day offered no benefit in prevention of endoscopic recurrence after surgery for ileal/ileocaecal fibrostenotic CD, but decreased the recurrence rate in patients who had undergone surgery for disease activity (recurrence rate $32 \%$ versus $65 \%$ respectively, $\mathrm{p}=0.047){ }^{41}$

Cortot and colleagues ${ }^{42}$ used budesonide to switch patients with steroid dependent CD from systemic steroids. Introduction of budesonide during the steroid tapering decreased steroid related side effects and maintained remission.

\section{Adverse events}

Budesonide CIR $9 \mathrm{mg} /$ day induced significantly less corticosteroid associated side effects compared to prednisolone. Median plasma cortisol concentrations in patients treated with budesonide $9 \mathrm{mg}$ and $15 \mathrm{mg}$ were reduced below baseline after two weeks and remained low throughout the study; budesonide $3 \mathrm{mg}$, however, did not influence the adrenocortical axis. Budesonide $9 \mathrm{mg} /$ day affected plasma cortisol concentrations less than prednisolone $40 \mathrm{mg}$ /day. In the Rutgeerts and Campieri studies, plasma cortisol concentrations were significantly lower in the prednisolone group than in the budesonide group after two, four, and eight weeks. The proportion of patients with plasma cortisol concentrations below the normal range was significantly higher in the prednisolone group at all times.

\section{SUMMARY}

The role of salicylates is well established in UC, but recent evidence has challenged it in CD, mainly in maintenance of remission and prevention of postoperative relapse. New steroids are a valid alternative to old steroids and salicylates in the treatment of active UC and CD, but are not effective in maintenance of remission.

In the past two decades, salicylates have been established in a number of controlled clinical trials as the main drug for treatment of UC. With the aim of achieving the same efficacy of SSP but without its major side effects, various preparations of new salicylates (such as mesalazine, olsalazine, and balsalazide) have been formulated, in order to assure targeted release, minor discomfort, and safety in use. New topical formulations have improved the choice, depending on the extent of disease. In treatment of CD the role of new salicylates is more complex. Mesalazine has been effective in the treatment 
of mild to moderate active $C D$, but failed to maintain remission. Its role in the prevention of postoperative relapse has recently been challenged and the discussion is still open.

Glucocorticoids are the main therapy in active UC and CD, but two open questions concern steroid dependence and steroid related side effects. The new steroids such as budesonide and BDP are characterised by high topical efficacy, because of rapid uptake by mucosal tissue and high GCS affinity, while minimising the risk of systemic effects by virtue of efficient hepatic inactivation. These features help to ensure that the products are well tolerated and patient compliance is maintained. Several studies have shown that topical budesonide or BDP are as effective in the treatment of distal UC as traditional steroids, with no effects on cortisol production. When administered as an oral, controlled release formulation, budesonide $9 \mathrm{mg}$ is as effective as prednisolone $40 \mathrm{mg}$ and more effective than mesalazine $4 \mathrm{~g}$ in active, mild to moderate CD. Moreover, budesonide is useful in steroid dependent CD. Unfortunately, it prolonged the time to relapse but failed to maintain remission in CD and prevent postoperative relapse. These studies, nevertheless, showed that the drug is safe in long term treatment.

\section{REFERENCES}

1 Svartz N. Salazopyrin, a new sulfanilamide preparation: A. Therapeutic results in rheumatic polyarthritis. B. Therapeutic results in ulcerative colitis. C. Toxic manifestations in treatment with sulfanilamide preparation. Acta Med Scand 1942;1 10:557-90

2 Azad Khan AK, Piris J, Truelove SC. An experiment to determine the active therapeutic moiety of sulphalasazine. Lancet 1977;2:892-5.

3 Sutherland LR, Roth DE, Beck PL. Alternatives to sulfasalazine: a meta-analysis of 5-ASA in the treatment of ulcerative colitis. Inflamm Bowel Dis 1997; 3:65-78.

4 Green JRB, Gibson JA, Kerr GD, et al. Maintenance of remission of ulcerative colitis: a comparison between balsalazide $3 \mathrm{~g}$ daily and mesalazine $1.2 \mathrm{~g}$ daily over 12 months. Aliment Pharmacol Ther 1998;12:1207-16

5 Green JRB, Lobo AJ, Holdsworth CD, et al. Balsalazide is more effective and better tolerated than mesalamine in the treatment of acute ulcerative colitis. Gastroenterology 1998;114:15-22.

6 Campieri M, Gionchetti P, Belluzzi A, et al. Optimum dosage of 5 -aminosalicylic acid as rectal enemas in patients with active ulcerative colitis. Gut 1991;32:929-81.

7 Marshall JK, Irvine EJ. Putting rectal 5-aminosalicylic acid in its place: the role in distal ulcerative colitis. Am J Gastroenterol 2000;95:162836 .

8 Cohen RD, Woseth DM, Thisted RA, et al. A meta-analysis and overview of the literature on treatment options for left-sided ulcerative colitis and ulcerative proctitis. Am J Gastroenterol 2000;95:1263-76.

9 Marshal JK, Irvine EL. Rectal corticosteroids versus alternative treatments in ulcerative colitis: a meta-analysis. Gut 1997;40:775-81

10 Marshal JK, Irvine EL. Rectal aminosalicylate therapy for distal ulcerative colitis: a meta-analysis. Aliment Pharmacol Ther 1995;9:293-300.

11 Gionchetti P, Rizzello F, Venturi A, et al. Comparison of oral with rectal mesalazine in the treatment of ulcerative proctitis. Dis Colon Rectum 1998;41:93-7.

12 Campieri M, Gionchetti P, Belluzzi A, et al. 5-Aminosalicylic acid as enemas or suppositories in distal ulcerative colitis? J Clin Gastroenterol 1988;10:406-9

13 Campieri $M$, Lanfranchi GA, Brignola $C$, et al. Retrograde spread of 5 -aminosalicylic acid enemas in patients with active ulcerative colitis. Dis Colon Rectum 1986;29:108-10

14 Campieri M, Gionchetti P, Belluzzi A, et al. 5-Aminosalicylic acid suppositories in the management of ulcerative colitis. Dis Colon Rectum 1989;32:398-9.

15 Safdi M, DeMicco M, Sninsky C, et al. A double-blind comparison of oral versus rectal mesalamine versus combination therapy in the treatment of distal ulcerative colitis. Am J Gastroenterol 1997;92:1867-71.

16 Campieri M, Cottone M, Miglio F, et al. Beclomethasone dipropionate enemas versus prednisolone sodium phosphate enemas in the treatment of distal ulcerative colitis. Aliment Pharmacol Ther 1998;12:361-6.
17 Mulder CJJ, Fockens P, Van der Heide H, Tytgat GNJ. A controlled randomized trial of beclomethasone dipropionate $(3 \mathrm{mg})$ versus 5 -aminosalicylic acid $(1 \mathrm{~g})$ versus the combination of both $(3 \mathrm{mg} / 1 \mathrm{~g})$ as retention enemas in active distal ulcerative colitis. Eur J Gastroenterol Hepatol 1996:8:549-53.

18 Cammà $C$, Giunta $M$, Rosselli $M$, et al. Mesalamine in the maintenance treatment of Crohn's disease: a meta-analysis adjusted for confounding variables. Gastroenterology 197;113:1465-73.

19 Caprilli R, Andreoli A, Capurso L, et al. Oral mesalazine (5-aminosalicylic acid; Asacol) for the prevention of post-operative recurrence of Crohn's disease. Gruppo Italiano per lo Studio del Colon e del Retto (GISC). Aliment Pharmacol Ther 1994:8:35-43.

20 McLeod RS, Wolff BG, Steinhart AH, et al. Prophylactic mesalamine treatment decreases postoperative recurrence of Crohn's disease. Gastroenterology 1995;109:404-13

21 Gendre JP, Mary JY, Florent C, et al. Oral mesalamine (pentasa) as maintenance treatment in Crohns' disease: a multicenter placebo controlled study. Gastroenterology 1993;104:435-9.

22 Sutherland LR, Martin F, Bailey R, et al. A randomized placebo-controlled double blind trial of mesalamine in the maintenance of remission in Crohn's disease. Gastroenterology 1997:1 12:1069-77.

23 Brignola C, Cottone M, Pera A, et al. Mesalamine in the prevention of endoscopic recurrence after intestinal resection for Crohn's disease. Gastroenterology 1995;108:345-9.

24 Lochs H, Mayer M, Fleig WE, et al. Prophylaxis of postoperative relapse in Crohn's disease with mesalamine: European Cooperative Crohn's Disease Study VI. Gastroenterology 2000;1 18:264-73.

25 Cottone M, Camma C. Mesalamine and relapse prevention in Crohn's disease. Gastroenterology 2000;11 9:597.

26 Sutherland LR. Reply. Gastroenterology 2000;1 19:597.

27 Summers RW, Switz DM, Sessions JT Jr, et al. National Cooperative Crohn's disease study; results of drug treatment. Gastroenterology 1979:77:847-69.

28 Malchow H, Ewe K, Brandes JW, et al. European Cooperative Crohn's disease study (ECDS): results of drug treatment. Gastroenterology 1984;86:249-66.

29 Modigliani R, Mary JY, Simon JF, et al. Clinical, biological and endoscopic picture of attacks of Crohn's disease. Evolution on prednisolone. Gastroenterology 1990;98:811-18.

30 Brignola C, De Simone G, Belloli C, et al. Steroid treatment in active Crohn's disease: a comparison between two regimens of different duration. Aliment Pharmacol Ther 1994;8:465-8.

31 Munkholm P, Langholz E, Davidsen M, et al. Frequency of glucocorticoid resistance and dependency in Crohn's disease. Gut 1994;35:360-2.

32 Sjödahl R, Jansen J, Nilsson $M$, et al. Pharmacokinetics of budesonide CIR capsules in patients after single dose and after repeated administration of $4.5 \mathrm{mg}$ twice daily. Report no. 08-CR-3016. Lund, Sweden: Astra Draco AB, 1995.

33 Cvetkovic S, Edsbacker S, Wollmer $P$, et al. Food does not alter site of absorption of budesonide from controlled ileal release capsules. Gut 1995;37(suppl 2):A51.

34 Löfberg R, Danielsson $\AA$, Salde L. Oral budesonide in active Crohn's disease. Aliment Pharmacol Ther 1993;7:611-16.

35 Greenberg GR, Feagan BG, Martin F, et al. Oral budesonide for active Crohn's disease. N Engl J Med 1994;331:836-41.

36 Rutgeerts $\mathbf{P}$, Löfberg $\mathrm{R}$, Malchow $\mathrm{H}$, et al. A comparison of budesonide with prednisolone for active Crohn's disease. N Engl J Med 1994;331:842-5

37 Campieri M, Ferguson A, Doe W, et al. Oral budesonide is as effective as oral prednisolone in active Crohn's disease. Gut 1997:41:209-14.

38 Thomsen $0 \varnothing$, Cortot A, Jewell D, et al. A comparison of budesonide and mesalamine for active Crohn's disease. N Engl J Med 1998;339:370-4

39 Löfberg R, Rutgeerts $\mathrm{P}$, Malchow $\mathrm{H}$, et al. Budesonide prolongs time to relapse in ileal and ileocaecal Crohn's disease. A placebo controlled one year study. Gut 1996;39:82-6.

40 Greenberg GR, Feagan BG, Martin F, et al. Oral budesonide as maintenance treatment for Crohn's disease: a placebo-controlled, dose-ranging study. Gastroenterology 1996;110:45-51.

41 Hellers G, Cortot A, Jewell D, et al. Oral budesonide for prevention of postsurgical recurrence in Crohn's disease. Gastroenterology 1999; 1 16:294-300.

42 Cortot A, Colombel FG, Rutgeerts $\mathrm{P}$, et al. Switch from systemic steroids to budesonide in steroid dependent patients with inactive Crohn's disease. Gut 2001;48:186-90. 